Nuclear Science and Technology Division

\title{
Hydrofluoric Acid Corrosion Study of High-Alloy Materials
}

P. E. Osborne*

A. S. Icenhour

G. D. Del Cul

Date Published: August 2002

Prepared by the

OAK RIDGE NATIONAL LABORATORY

Oak Ridge, Tennessee 37831-6285 managed by

UT-BATTELLE, LLC

for the

U.S. DEPARTMENT OF ENERGY

under contract DE-AC05-00OR22725

\footnotetext{
*A4 Engineering, Inc., Knoxville, Tennessee
} 


\section{CONTENTS}

LIST OF FIGURES …...............................................................................

LIST OF TABLES .......................................................................................... vii

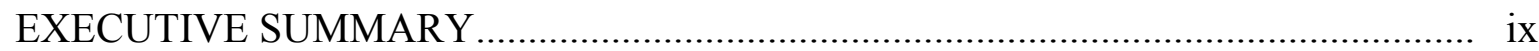

1. INTRODUCTION …............................................................................ 1

2. EXPERIMENTAL ..................................................................................... 3

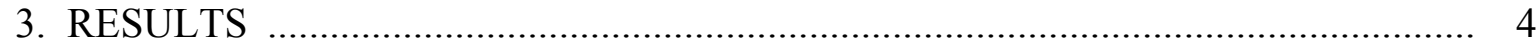

3.1 SHORT-TERM TESTING _.................................................................. 4

3.2 LONGER-TERM TESTING ................................................................. 5

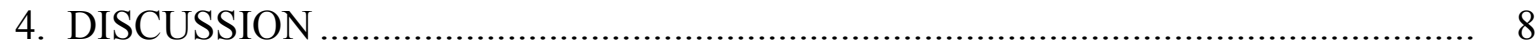

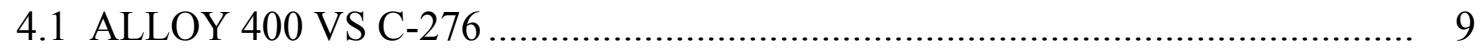

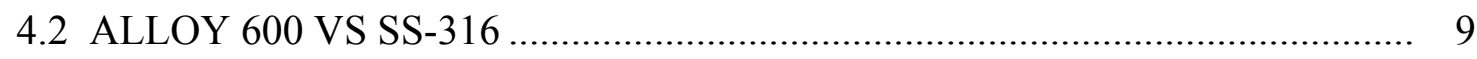

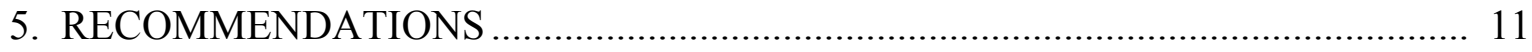

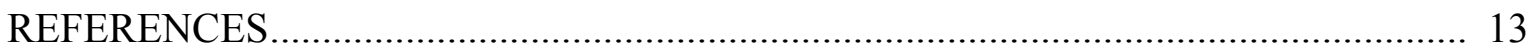




\section{LIST OF FIGURES}

\section{Figure}

Page

1 Alloy corrosion rates in $33 \% \mathrm{HF}$ at ambient temperature .................................. 6

2 Comparison of (a) alloy C-276 and alloy 400 coupons and (b) alloy 600 and SS-316 coupons at beginning and completion of testing .................................... 7

3 Effect of $\mathrm{O}_{2}$ and temperature on the corrosion rate of alloy 400 in $49 \%$ HF.......... 8

4 Effect of temperature on the corrosion of alloy 400 and alloy C-276

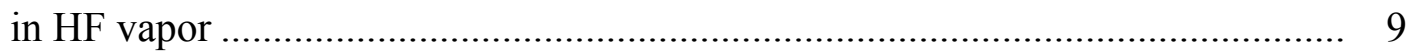

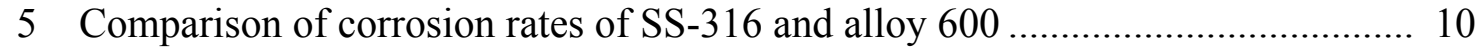

6 Effect of temperature and concentration on corrosion of alloy 600 and SS-316 when immersed in 1 and $12 \mathrm{wt} \% \mathrm{HF}$. 


\section{LIST OF TABLES}

Table

Page

1 Approximate chemical compositions of selected alloys ................................ 2 


\section{EXECUTIVE SUMMARY}

A corrosion study was conducted on samples of high-alloy materials currently used in the Molten Salt Reactor Experiment Conversion Project (CP). This process involves converting ${ }^{233} \mathrm{U}$ to a stable oxide. The hydrolysis of the uranium compounds produces concentrated hydrofluoric acid (HF), which has strong corrosion capabilities. This test was conducted to gain a better understanding of corrosion rates of different high-alloy materials in concentrated HF and to help formulate a change-out schedule for CP parts.

The CP involves many parts and materials of construction, but the parts of most concern are the valves. These valves are typically constructed of Monel 400 bodies and stem tips and Inconel 600 bellows. Until recently, the bellows also had a stainless steel alloy 316 (SS-316) flange ring welded to the base. This use of SS-316 resulted in many failures in laboratory experiments involving the transfer of HF. Upon discovery of this situation, the manufacturers of the valves immediately began replacing all the original bellows with bellows that had all-inconel 600 construction in the wetted areas. Hastelloy C-276 valve bodies and stem tips have recently become available, and it is now desirable to determine whether it is more cost-effective to change out the valve modules immediately or to wait for scheduled replacement.

A basic HF corrosion test was proposed to compare corrosion rates of several high-alloy materials. Because much of the alloy 400 in the system had been gold plated, some gold-plated alloy 400 coupons were included. Due to time and funding limitations, actual $\mathrm{CP}$ variables such as temperature and pressure were not duplicated. Instead, a simple partial-immersion test at ambient temperature was conducted. The coupons were partially immersed in separate beakers of $33 \mathrm{wt} \% \mathrm{HF}$. During the short-term test (the first 7 days), the coupons were cleaned, dried, and weighed daily. The HF was also changed if it showed any discoloration. The longer-term test involved cleaning, drying, and weighing the coupons at 1-week intervals for a period of 3 weeks. This test was designed to provide information on the corrosion of different alloys in the $\mathrm{CP}$ and to derive some idea of their expected lifetimes in the operating environment. 
Short-term results indicated a severe attack on the SS-316 below the liquid line. The average corrosion rate for this alloy was 1600-1800 mils per year (mpy) during the first week. The alloy 600 coupons performed somewhat better, averaging 120 mpy the first week. This alloy experienced attack primarily at the liquid/vapor interface and in the region above the liquid. The gold-plated alloy 400 experienced the third-highest corrosion rate. The gold-plated coupons had an average corrosion rate of 23 mpy over the first 7 days, and one coupon had lost most of its plating by day 4. The unplated alloy 400 and alloy C-276 coupons performed best during the short-term test. Both alloys averaged less than 10 mpy during the first week.

Results from the longer-term test tended to duplicate those from the short-term test in regard to the most- and least-affected coupons. SS-316 again experienced the highest rate of corrosion. The SS-316 coupons lost approximately $60 \%$ of their mass, mostly below the liquid, leading to an average corrosion rate of $550 \mathrm{mpy}$ at the end of the fourth week. The corrosion deposits did help to slow the corrosion rate and protect the metal surface. The alloy 600 coupons had an average corrosion rate of $128 \mathrm{mpy}$ by the end of the test and had turned completely black in the vapor. The gold-plated and unplated alloy 400 coupons ended the test with nearly identical corrosion rates averaging 29 mpy. Alloy C-276 outperformed all other alloys, with an average corrosion rate of 5 mpy, and appeared intact and virtually unaffected by the testing. 


\section{INTRODUCTION}

A corrosion study involving high-alloy materials and concentrated hydrofluoric acid (HF) was conducted in support of the Molten Salt Reactor Experiment Conversion Project (CP). The purpose of the test was to obtain a greater understanding of the corrosion rates of materials of construction currently used in the CP vs those of proposed replacement parts. Results of the study will help formulate a change-out schedule for CP parts.

The CP will convert slightly less than $40 \mathrm{~kg}$ of ${ }^{233} \mathrm{U}$ from a gas $\left(\mathrm{UF}_{6}\right)$ sorbed on sodium fluoride pellets to a more stable oxide $\left(\mathrm{U}_{3} \mathrm{O}_{8}\right)$. One by-product of the conversion is the formation of concentrated HF. Six moles of highly corrosive HF are produced for each mole of $\mathrm{UF}_{6}$ converted. This acid is particularly corrosive to most metals, elastomers, and silica-containing materials.

A common impurity found in ${ }^{233} \mathrm{U}$ is ${ }^{232} \mathrm{U}$. This impurity isotope has several daughters that make the handling of the ${ }^{233} \mathrm{U}$ difficult. Traps of ${ }^{233} \mathrm{U}$ may have radiation fields of up to $400 \mathrm{R}$ at contact, a situation that makes the process of changing valves or working on the $\mathrm{CP}$ more challenging. It is also for this reason that a comprehensive part change-out schedule must be established.

Laboratory experiments involving the repeated transfer of HF through 1/2-in. metal tubing and valves have proven difficult due to the corrosivity of the HF upon contact with all wetted parts. Each batch of HF is approximately $1.5 \mathrm{~L}$ of $33 \mathrm{wt} \% \mathrm{HF}$ and is transferred most often as a vapor under vacuum and at temperatures of up to $250^{\circ} \mathrm{C}$. Materials used in the HF side of the CP include Hastelloy C-276 and Monel 400 tubing, Haynes 230 and alloy C-276 vessels, and alloy 400 valve bodies with Inconel (alloy 600) bellows. The chemical compositions of the metals discussed in this report are displayed in Table 1.

Of particular concern are the almost 30 vendor-supplied UG valves that have the potential for exposure to HF. These valves have been proven to have a finite life due to failure, most often at the bellows flange ring. It was discovered that the entire bellows assembly was not all alloy 600 but that alloy 600 bellows had been welded to a stainless steel alloy 316 (SS-316) flange ring. A previous study documents and addresses this

problem. ${ }^{1}$ The fabricators of the valves immediately corrected the problem and began 
fabricating all wetted parts of the bellows assembly from alloy 600. At the same time, the fabricators began to make alloy $\mathrm{C}-276$ valve bodies and stem tips available for sale. This material is known to be superior to the alloy 400 valve bodies and stem tips of the standard UG valves that had already been installed in the CP. A decision was made to purchase alloy $\mathrm{C}-276$ bodies and stem tips and to change out those alloy 400 components that had already been installed. Due to the enormity of this task (both in terms of time and money), it was desirable to determine the longevity of alloy C-276 vs alloy 400 components in a side-by-side comparison. Also of interest was the question of how long the new (all-alloy 600) bellows would last in comparison with the original alloy 600/SS-316 bellows.

A basic HF corrosion test was proposed to compare corrosion rates of several high-alloy materials. Because much of the alloy 400 in the system had been gold plated, some gold-plated alloy 400 coupons were included. Due to time and funding limitations, actual CP variables such as temperature and pressure were not duplicated. Instead, a simple partial-immersion test at ambient temperature was conducted. The purpose of this test was to gain information on the rate of corrosion of different alloys in the $\mathrm{CP}$ and to attempt to derive some idea of their expected lifetimes in the operating environment.

Table 1. Approximate chemical compositions of selected alloys

\begin{tabular}{cc}
\hline Alloy & Composition (wt \%) \\
\hline Monel 400 & $67 \mathrm{Ni}-31.5 \mathrm{Cu}-1.2 \mathrm{Fe}$ \\
Inconel 600 & $76 \mathrm{Ni}-15.5 \mathrm{Cr}-8 \mathrm{Fe}$ \\
Hastelloy C-276 & $57 \mathrm{Ni}-16 \mathrm{Cr}-16 \mathrm{Mo}-4 \mathrm{~W}$ \\
Stainless steel 316 & $12 \mathrm{Ni}-17 \mathrm{Cr}-2.5 \mathrm{Mo}-1-2 \mathrm{Mn}-65 \mathrm{Fe}$ \\
\hline
\end{tabular}

Source: R. B. Rebak, J. R. Dillman, P. Crook, and C. V. V. Shawber, "Corrosion Behavior of Nickel Alloys in Wet Hydrofluoric Acid,” Mater. Corros. 52, 289-297 (2001). 


\section{EXPERIMENTAL}

Several variables contribute to the corrosion rate of HF upon contact with metals. Some of these include concentration of HF, time, temperature, available oxygen, vapor vs liquid exposure, impurities in the HF and the materials tested, flow, agitation, and erosion. Some of these variables can cause a thousand-fold increase in the corrosion rate, depending on the metal tested.

A concentration of $33 \mathrm{wt} \% \mathrm{HF}$ was used because this is the average concentration expected throughout the CP. A testing period of 1 month was chosen because it gave opportunities to study corrosion rates in both short- and longer-term settings. The first week of testing involved cleaning and weighing samples daily, while specifications for weeks 2-4 required weekly cleaning and weighing of samples. Because of the complexity and cost of fabricating a system that could duplicate actual temperatures and flows expected in the $\mathrm{CP}$, the test was run at ambient temperature $\left(\sim 23^{\circ} \mathrm{C}\right)$ and in beakers.

Sheets of each of the metals of interest (1/8 in. thick) were obtained and cut into 1 - by 2-in. coupons. Sample coupons from each batch were sent to a weld inspector for confirmation of composition. Two coupons were then chosen from each batch and cleaned with warm water, ethanol, and acetone. They were then allowed to air dry before being weighed and placed in a new 50-mL polypropylene beaker. Each coupon was assigned to its own beaker and had an accompanying pair of new polyethylene tongs for any handling that was required.

Two of the alloy 400 coupons were sent to Stricker Refinishing Company in Cleveland, Ohio, to be gold plated. This was done per MIL-G-45204C, Type 1, Grade A, Class 1, which is the current electrolytic gold-plating standard.

A "mother solution" was prepared using reagent-grade HF and deionized water to form a solution of $33 \mathrm{wt} \% \mathrm{HF}$. The solution was mixed thoroughly in air and kept in a new polyethylene bottle to avoid any cross-contamination.

Approximately $30 \mathrm{~mL}$ of mother solution was added to each sample beaker. This left approximately one-half of each of the coupons immersed and one-half exposed to air. Observations were recorded, and the coupons were left to react for 20-24 h, after which time each coupon was removed and studied before being rinsed and dried. If visible 
corrosion appeared on the coupon, it was immersed in deionized water and ultrasonically cleaned. After cleaning was completed, each coupon was again rinsed with deionized water and ethanol and allowed to air dry. After drying, all coupons were then weighed and reimmersed in a fresh solution of HF (if the solution was discolored) or reimmersed in the same solution (if it remained clear). This procedure was repeated daily throughout the first week and then repeated weekly for weeks 2-4. Observations were recorded and coupons were photographed throughout the test. Corrosion rates were calculated based on ASTM Standard G31-72, Standard Practice for Laboratory Immersion Corrosion Testing of Metals, and ASTM Standard G1-90, Standard Practice for Preparing, Cleaning, and Evaluating Corrosion Test Specimens.

A very resilient corrosion product appeared on the surface of some coupons. If the corrosion could not be ultrasonically cleaned from the surface of the coupon, an attempt was made to carefully scrub or pry off the corrosion deposit without disturbing the metal surface. This process worked for most materials; however, the SS-316 coupons proved to be particularly difficult to clean completely.

\section{RESULTS}

\subsection{Short-Term Testing}

The short-term test involved checking the samples daily for the first 7 days and recording any changes. The SS-316 coupons were aggressively attacked below the liquid line in an exothermic reaction and, within hours, had caused the HF to turn a dark green. Dark green corrosion deposits began building up below the liquid line almost immediately. These deposits were found to be insoluble (or very slightly soluble) in water and acetone. The alloy 600 coupons were attacked primarily at the liquid/vapor interface and, by the following day, had caused the HF to turn a light green. The coupons formed a thin black deposit at the liquid line and eventually up to the top of the coupon. One of the gold-plated alloy 400 coupons appeared unaffected, while the other had some copper precipitate on the gold in contact with the liquid. By the third day of the test, this coupon had lost much of the gold plating on one side. The coupons followed this same 
pattern for the first 5 days. On day 6, the alloy 400 and gold-plated alloy 400 coupons had some green crystals that formed at the top. Also on day 6 , the gold came off the gold-plated alloy 400 coupons in large pieces.

Corrosion rates for the materials differed greatly in the first week. The corrosion rate for the alloy 600 coupons increased for the first 3-4 days before leveling off at approximately 120 mils per year (mpy). The SS-316 experienced a severe and immediate attack below the liquid, which led to a corrosion rate of about 1600-1800 mpy during the first week. The rate tapered off slowly as the week progressed but may also have been affected by corrosion deposits that could not be removed. Ranking third in terms of corrosion effect were the gold-plated alloy 400 coupons. By day 3-4, they were averaging a corrosion rate of almost 23 mpy, with the coupon that lost the gold plating measuring almost double the corrosion rate of the unaffected coupon. The gold loss could have led to slightly inflated numbers but could not account for all of the additional corrosion experienced. The alloy C-276 and alloy 400 coupons were largely unaffected during the first week and had a corrosion rate of less than 10 mpy.

\subsection{Longer-Term Testing}

Results from the longer-term testing, for the most part, led to a settling out of corrosion rates. The alloy 400 coupons were an exception to this observation, as their corrosion rate continued to increase throughout the test. The corrosion rates for all of the coupons (except for the SS-316) can be seen in Fig. 1. Trends for SS-316 were omitted because the corrosion rate was so much greater than that for the others. Photographs of the coupons at the beginning and end of the test appear as Figs. $2 \mathrm{a}$ and $2 \mathrm{~b}$.

The SS-316 coupons again showed the highest corrosion rate and settled out at approximately 550 mpy by the fourth week. Over the course of the test, these coupons lost an average of $60 \%$ of their weight, leaving them with very little mass below the level of the liquid. The HF in the SS-316 beakers was always dark green, and a heavy precipitate was observed at the bottom of the beakers. 


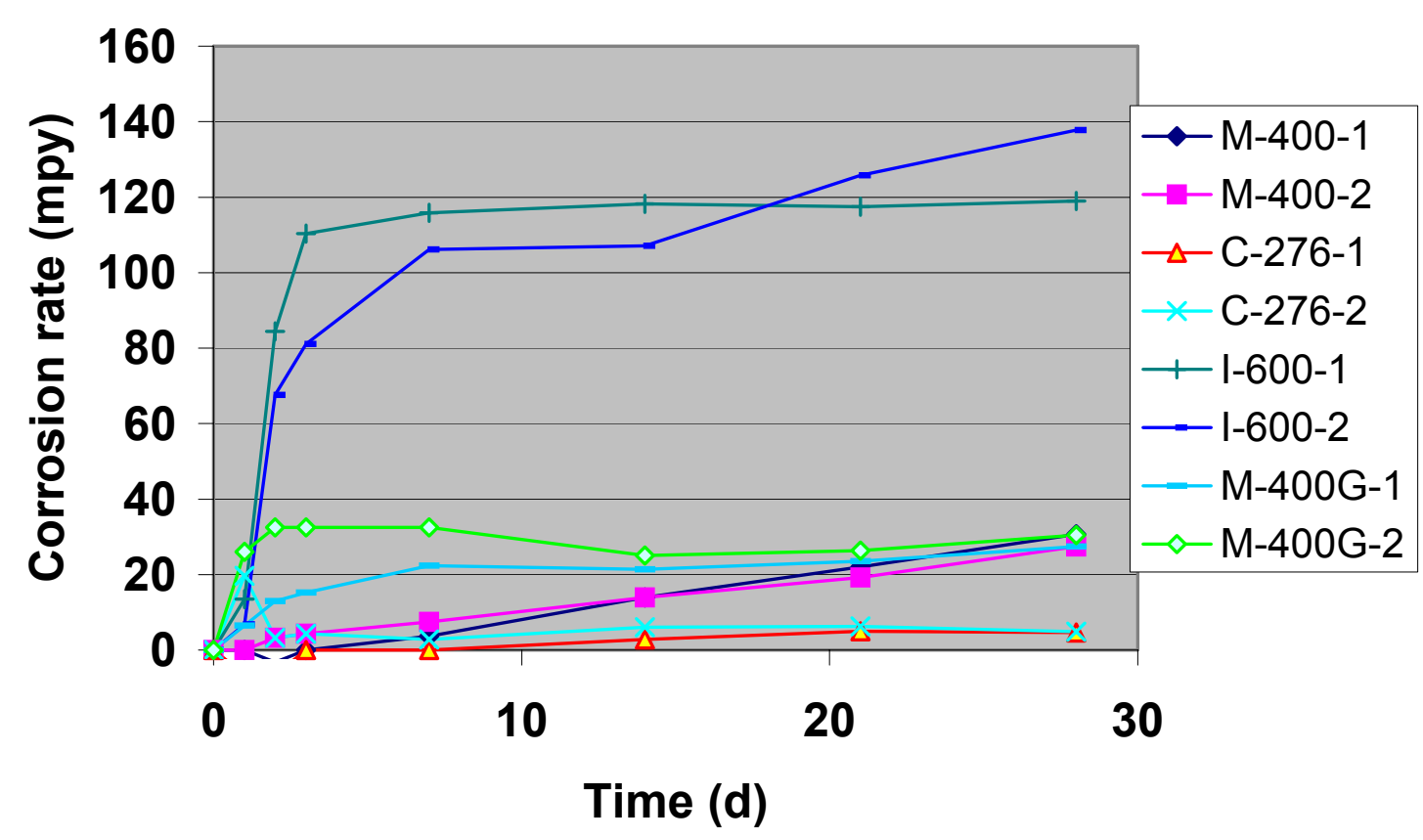

Fig. 1. Alloy corrosion rates in $33 \% \mathrm{HF}$ at ambient temperature.

Alloy 600 coupons performed better than the SS-316 but still experienced moderate corrosion rates. One coupon had an increasing corrosion rate starting at week 2 , while the rate for the other remained steady after day 3 . The coupons averaged a corrosion rate of 128 mpy at week 4 and appeared black in the area exposed to vapor. The corrosion deposits appeared to be soluble in water and were removed during ultrasonic cleaning.

The alloy 400 coupons and the gold-plated alloy 400 coupons had very similar corrosion rates. The corrosion rate for the unplated coupons continued to increase steadily throughout the entire test, while the gold-plated coupons had a corrosion rate that peaked at day 3 and then began to increase again starting in the third week of testing. By the end of the fourth week, the corrosion rates of the plated and unplated alloy 400 coupons were almost identical and averaged 29 mpy.

Alloy C-276, as expected, outperformed all other alloys. Coupons made of this material had a slight increase in corrosion rate for the first 2 weeks. After this period, the rate leveled off, and the coupons ended the test with an average corrosion rate of just below 5 mpy. Alloy C-276 did form a thin green film in the vapor during weeks 3 and 4, but this film was easily removed by ultrasonic cleaning. 


\section{Alloy C-276}

(a)

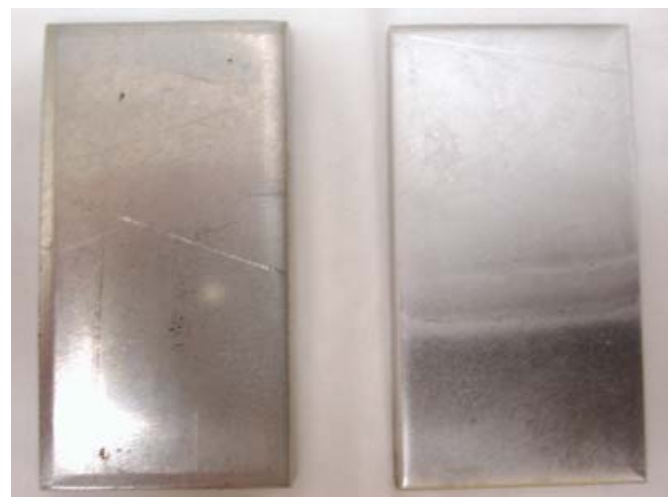

Alloy 600

(b)

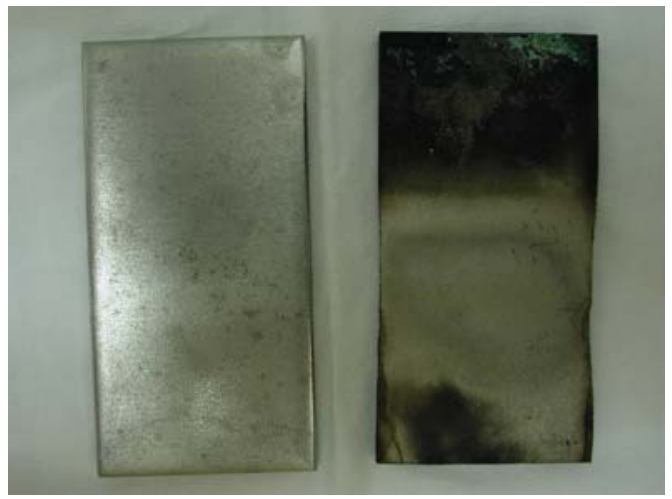

Alloy 400

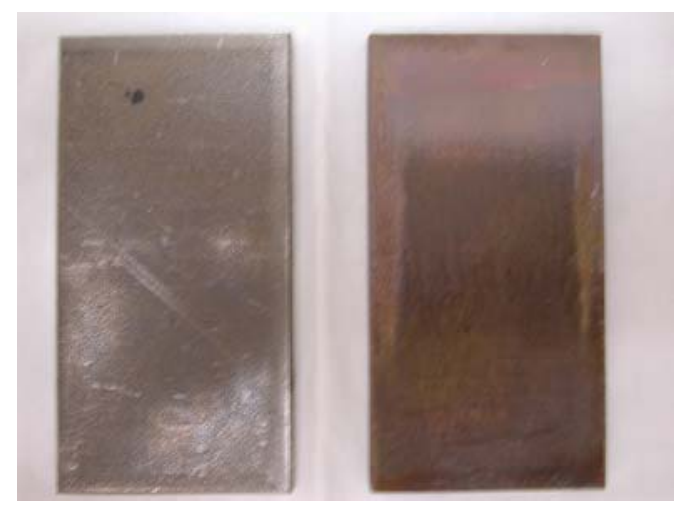

SS-316

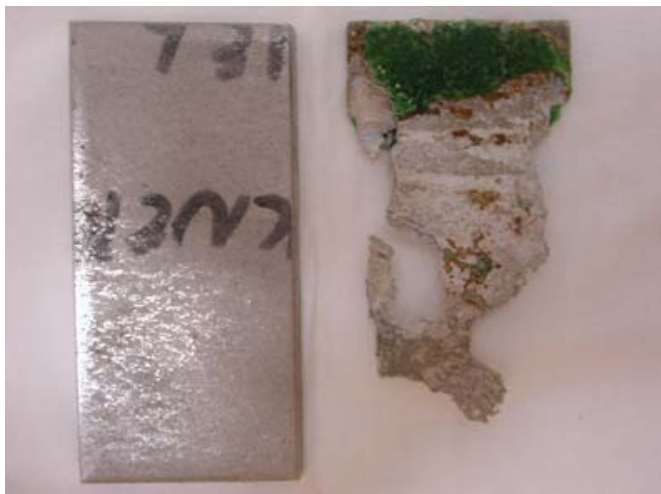

Fig. 2. Comparison of (a) alloy C-276 and alloy 400 coupons and (b) alloy 600 and SS-316 coupons at the beginning and completion of testing.

\section{DISCUSSION}

Figure 1 shows the corrosion rates of all metals tested except for the SS-316. These rates are indicative of what might be expected if the $\mathrm{CP}$ were operated at ambient temperature and under a partial atmosphere of oxygen. The CP, however, operates at $200^{\circ} \mathrm{C}$ during most HF transfers and is normally kept under a nitrogen blanket. Very small parts of the system are sometimes exposed to air. To better understand the true 
dynamics expected, it is important to take into account the effects of temperature and other important variables that this test was not able to duplicate. A literature search was done to compare the findings of other researchers with the results from this test and to factor in the other variables.

\subsection{Alloy 400 vs C-276}

One of the objectives of the study was to determine how much better alloy C-276 (vs alloy 400) UG valve bodies and stem tips performed. The ultimate goal was to determine how much longer the alloy C-276 valve would last in typical CP operations. To do this, other factors must be examined.

A comparison of the results of this test for alloy 400 and alloy C-276 initially suggests that there is very little difference. Alloy 400 actually performed better than alloy C-276 for the first 5 days. Thereafter, however, alloy C-276 performed better. According to the literature, alloy 400 does very well at ambient temperatures and in the absence of oxygen. According to Kane et al., however, alloy 400 corrodes rapidly with or without oxygen once temperatures reach $88-120^{\circ} \mathrm{C}$ (see Fig. 3, which is adapted from Ref. 2).

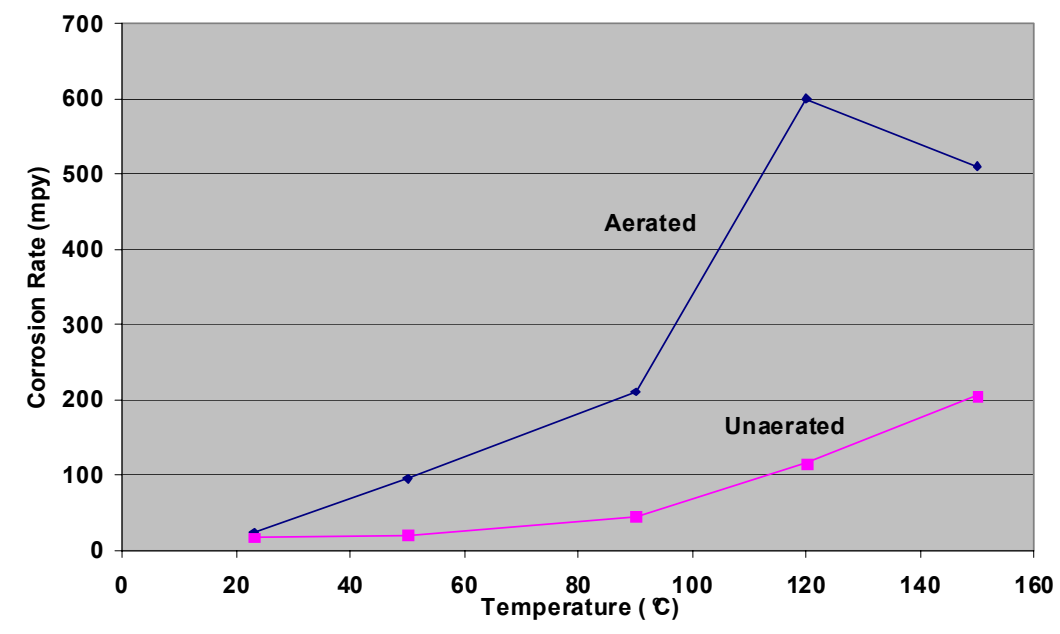

Fig. 3. Effect of $\mathrm{O}_{2}$ and temperature on the corrosion rate of alloy 400 in $49 \%$ HF. Adapted from R. D. Kane, S. M. Wilhelm, W. G. Ashbough, and R. G. Taraborelli, "Simulate Chemical Process Corrosion in the Laboratory," Chem. Eng. Prog. 89 (6), 65-70 (1993). 
Other studies found that the presence of oxygen in the HF vapor dramatically increased the corrosion rate of alloy 400. Alloy C-276 is also adversely affected by temperature but not nearly to the extent of alloy 400 . Rebak et al. found that the rates of corrosion of alloys C-276 and 400 diverge greatly as the temperature increases (see Fig. 4, which is adapted from Ref. 3). When the trend lines are followed to $200^{\circ} \mathrm{C}$, it is estimated that alloy 400 would have a corrosion rate almost 10 times that of alloy C-276. Several other reports support these results and show similar differences in corrosion rates between alloy 400 and various types of Hastelloy. ${ }^{4-6}$

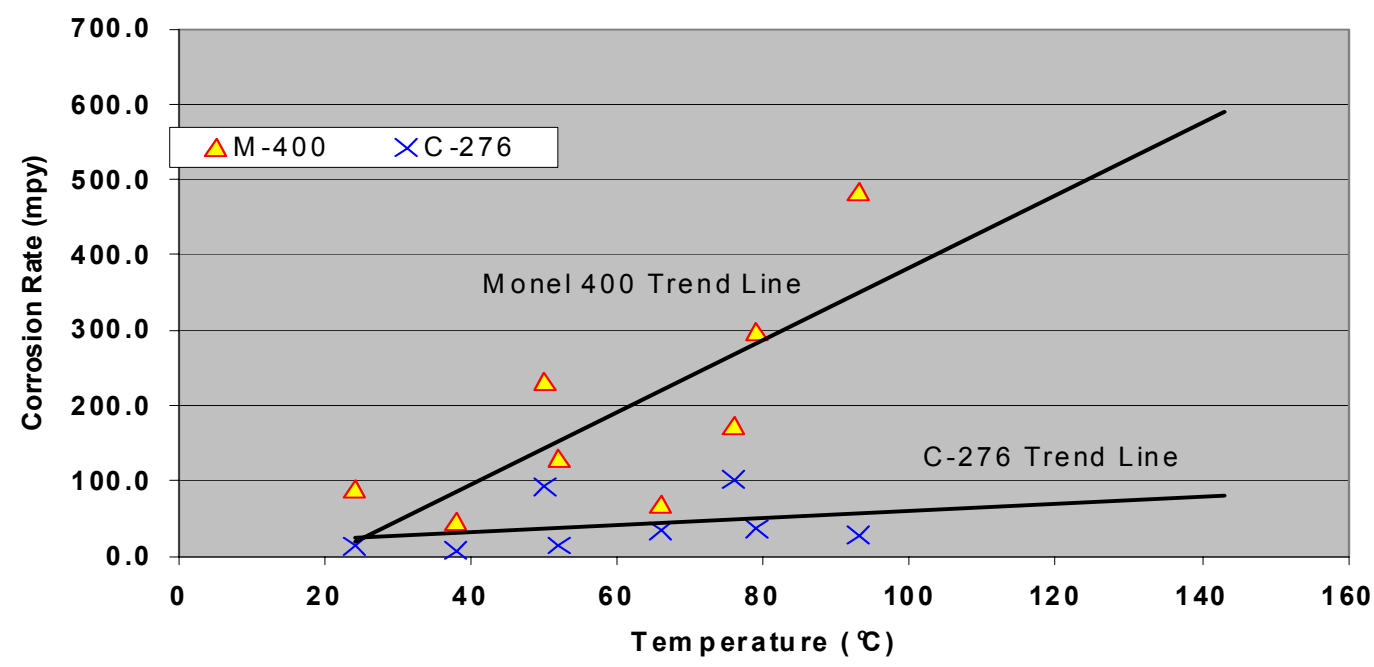

Fig. 4. Effect of temperature on the corrosion of alloy 400 and alloy C-276 in HF vapor. Adapted from R. B. Rebak, J. R. Dilman, P. Crook, and C. V. V. Shawber, "Corrosion Behavior of Nickel Alloys in Wet Hydrofluoric Acid," Mater. Corros. 52, 289-297 (2001).

\subsection{Alloy 600 vs SS-316}

Alloy 600 and SS-316 originally composed part of the wetted area making up UG bellows assemblies. The original bellows, which had been estimated to last at least four cycles in the $\mathrm{CP}$, are to be replaced with an all-alloy 600 bellows (wetted parts). It was desirable to determine how much better the alloy 600 bellows would perform and, ultimately, how many more cycles these new bellows might last. Again, it was important to consult literature studies to consider the many variables that were not examined in this test. 
The data from this test show a wide discrepancy in corrosion rates of alloy 600 and SS-316 from the first day forward. After 1 day, the SS-316 coupons averaged a corrosion rate almost 171 times that of alloy 600 . The corrosion rates gradually decreased for SS-316 and increased for the alloy 600 coupons until a steady fourfold difference was maintained. These rates are shown in Fig. 5. One important note about these results is that the SS-316 coupons accumulated a thick deposit of corrosion products that was not easily removed (see Fig. 2b). The deposit was most likely ferrous fluoride $\left(\mathrm{FeF}_{2} \bullet 8 \mathrm{H}_{2} \mathrm{O}\right)$, which is soluble only in $\mathrm{HF}$. Some of the decrease in the corrosion rate seen from day 7 forward can be attributed to this deposit, which helped shield the metal surface from further attack. Another study notes the same phenomenon, which caused the results for stainless steel to be somewhat skewed. ${ }^{6}$

The main area of attack occurs in different places for these alloys. SS-316 experiences the most severe attack below the liquid line, while alloy 600 experiences the greatest part of its attack in the vapor phase. Most of the available literature that includes data for both of these alloys cites immersion tests. Therefore, compared with the findings of this test, the literature results for SS-316 appear much worse while those for alloy 600 appear much better. A collection of data from two sources is charted in Fig. 6. These data show a correlation between severity of attack and temperature for SS-316, as well

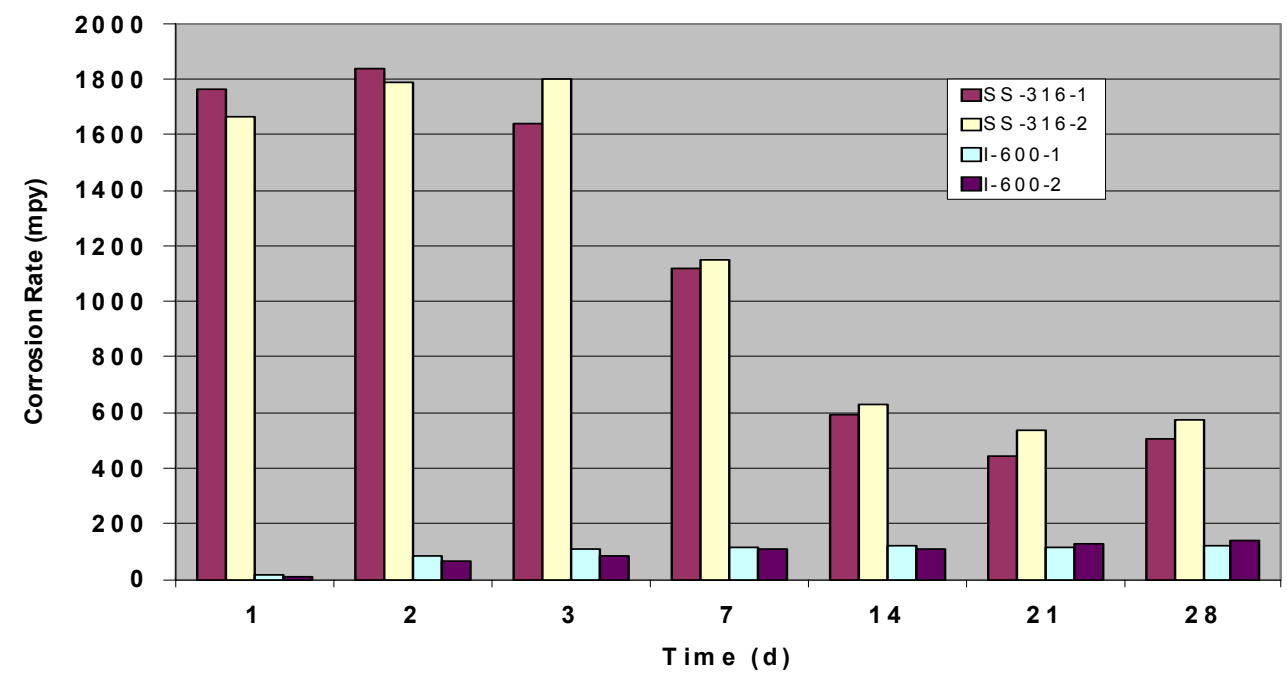

Fig. 5. Comparison of corrosion rates of SS-316 and alloy 600. 
as some correlation between the concentration of HF and the corrosion rate for this alloy. Neither of these variables appears to affect the corrosion rate of alloy 600 . The first three points for each alloy were collected from a test that immersed the alloys in $1 \mathrm{wt} \% \mathrm{HF}$. The last point for each alloy was from a test that used $12 \mathrm{wt} \% \mathrm{HF}$.

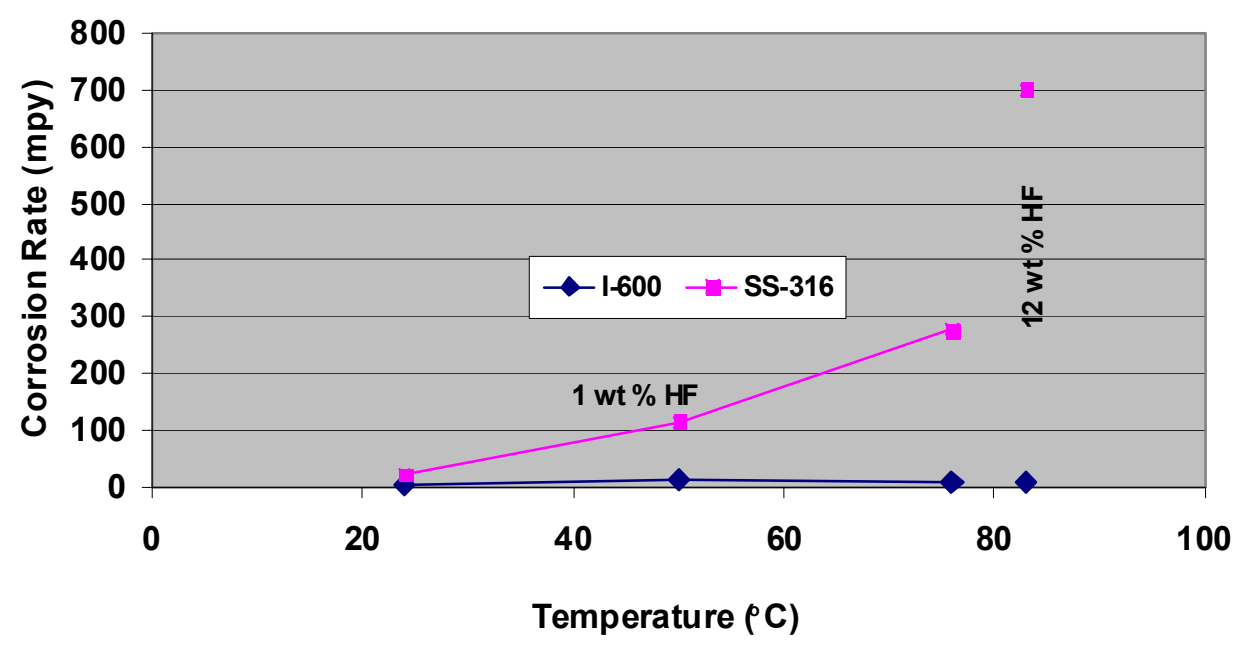

Fig. 6. Effect of temperature and concentration on corrosion of alloy 600 and SS-316 when immersed in 1 and 12 wt \% HF. Adapted from "Corrosion Resistance of Nickel-Containing Alloys in Hydrofluoric Acid, Hydrogen Fluoride, and Fluorine," INCO Corrosion Engineering Bulletin No. 5, International Nickel Co., Inc., New York, 1968; and S. J. Pawel, "Corrosion of High-Alloy Materials in Aqueous Hydrofluoric Acid Environments," Corrosion 50(12), 963-971 (1994).

\section{RECOMMENDATIONS}

The original objective of this study was to gain a better understanding of the corrosion rate of several high-alloy materials that are used in the CP. It was hoped that this information might then lead to a more informed decision about how often certain parts of the CP should be changed out. The first two materials that were compared were alloy 400 and alloy C-276. Data from this study and from the literature clearly indicate that alloy C-276 performs better in concentrated HF, and this superiority becomes even more pronounced as temperature and availability of oxygen increase. At the expected transfer temperature $\left(200^{\circ} \mathrm{C}\right)$, it is estimated that alloy C-276 will have a corrosion rate 
approximately 10 times lower than that of alloy 400. In contrast to the original plan to change out valve bodies, bellows, and stem tips every four runs, it would not be unreasonable to expect the new alloy $\mathrm{C}-276$ valve bodies and stem tips to last for the entire life of the CP.

The second issue addressed by this study was to determine how much longer the all-alloy 600 (Inconel) bellows might last as compared with the original alloy 600/SS316 bellows. This issue is somewhat more difficult, because most of the literature studies measured only the corrosion rate of immersed SS-316. In actual operations, most of the bellows in the CP will be subjected primarily to the vapor form of HF. Alloy 600 is definitely the better material at high temperatures and for concentrations of HF in the 1$60 \%$ range and is estimated to last four to seven times longer than the alloy 600/SS-316 mix. The schedule for the original bellows specified changing after every fourth run. Based on the data of this study and literature findings, it now appears that the bellows can be safely changed out at some time after run 16 but before run 28. It is recommended that those bellows subjected to the harshest environments within the $\mathrm{CP}$ be changed out after the 16th run and examined to determine the extent of corrosion. This procedure will provide the operator with valuable data concerning the change-out schedule for the remaining bellows. It is not inconceivable that some of the bellows might last throughout the entire campaign. 


\section{REFERENCES}

1. P. E. Osborne, A. S. Icenhour, and G. D. Del Cul, Corrosion Test Results for Inconel 600 vs Inconel/Stainless UG Bellows, ORNL/TM-2002/136, Oak Ridge National Laboratory, Oak Ridge, Tenn., August 2002.

2. R. D. Kane, S. M. Wilhelm, W. G. Ashbough, and R. G. Taraborelli, "Simulate Chemical Process Corrosion in the Laboratory," Chem. Eng. Prog. 89(6), 65-70 (1993).

3. R. B. Rebak, J. R. Dillman, P. Crook, and C. V. V. Shawber, "Corrosion Behavior of Nickel Alloys in Wet Hydrofluoric Acid," Mater. Corros. 52, 289-297 (2001).

4. "Corrosion Resistance of Nickel-Containing Alloys in Hydrofluoric Acid, Hydrogen Fluoride, and Fluorine," Inco Corrosion Engineering Bulletin No. 5, International Nickel Co., Inc., New York, 1968.

5. C. M. Schillmoller, "Select the Right Alloys for Hydrofluoric Acid Service," Chem. Eng. Prog. 94(11), 49-54 (November 1998).

6. S. J. Pawel, "Corrosion of High-Alloy Materials in Aqueous Hydrofluoric Acid Environments," Corrosion 50(12), 963-971 (1994). 


\section{INTERNAL DISTRIBUTION}

1. J. M. Begovich

2. C. W. Chase

3. G. E. Chitwood

4. J. M. Cosgrove

5. G. D. Del Cul

6. R. L. Faulkner

7. D. Foster

8. M. H. Haghighi, Bechtel Jacobs Company

9. J. N. Herndon

10. A. S. Icenhour

11. R. A. Kite

12. P. E. Osborne

13. B. A. Owen
14. J. H. Platfoot

15. S. A. Richardson

16. J. E. Rushton

17. D. W. Simmons

18. J. R. Travis

19. M. G. Branton, DOE ORNL Site Office

20. M. R. Jugan, DOE-ORO

21. S. R. Martin, DOE ORNL Site Office

22. Central Research Library

23. ORNL Laboratory Records

24-25. ORNL Laboratory Records-OSTI-RC

26. NSTD DMC

27. Conversion Project Files 